\title{
The Association Between Biliary Atresia and Cytomegalovirus Hepatitis
}

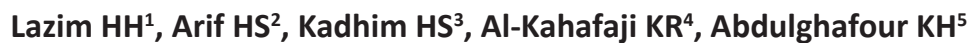

\begin{abstract}
Introduction: Biliary atresia (BA) is a disease characterized by a biliary obstruction of unknown origin. Viral agents have been proposed in the aetiology of BA such as cytomegalovirus (CMV). This virus also considered as a one of agents that can infect the liver and cause hepatitis. The aim of this study was to determine the role of CMV in children with both chronic hepatitis (negative for hepatitis B and C) and have biliary atresia in the same time. Material and Methods: A retrospective study done on 13 liver tissue paraffin blocks of children with chronic hepatitis (negative for hepatitis B and C) and biliary atresia (extra and intra). The diagnosis was based on the presence of HCMV protein (pp65) by using immunohistochemistry. Results: Immunohistochemistry for pp65 showed the liver tissue blocks were positive for 10 cases $(76.9 \%)$.The mild inflammation and moderate fibrosis were the highest among the cases. Conclusion: CMV is one of the important viruses that can causes hepatitis in infants (whom are negative for hepatitis $B$ and $C$ ), also this virus has significant role in pathogenesis of biliary atresia.
\end{abstract}

Key words: Cytomegalovirus, biliary atresia, hepatitis, immunohistochemistry, infants.

\section{Introduction}

B iliary atresia (BA) is a disease characterized by a biliary obstruction of unknown origin that presents in the neonatal period and it is the most frequent surgical cause of cholestatic jaundice in neonates, also it is a severe hepatobiliary disease in infancy characterized by a progressive, fibro-obliterative process affecting extrahepatic as well as intrahepatic bile ducts, leading to early liver cirrhosis ${ }^{1}$. The cause of BA remains unknown. Theories on pathogenesis include genetic predisposition, abnormal morphogenesis, vascular abnormalities, exposure to environmental toxins, viral infection, and autoimmune mediated bile duct destruction ${ }^{2}$.

Multiple viruses including hepatitis B, human papillomavirus, Epstein-Barr virus, cytomegalovirus (CMV), rotavirus and reovirus have been proposed in the etiology of BA. ${ }^{3,4,5,6}$. Cytomegalovirus (CMV) is a member of the Herpesviridae ${ }^{7}$. CMV infection is acquired either in the perinatal period and infancy or in adulthood through sexual contact, organ transplantation or blood transfusion ${ }^{8}$. CMV
'Hussam Hussain Lazim (M.Sc. Microbiology) College of Medicine, Al-Nahrain UniversityBaghdad, Iraq, ${ }^{2}$ Hala Sameh Arif (C.A.B.P. Pediatric) College of Medicine, Al-Nahrain UniversityBaghdad, Iraq, ${ }^{3}$ Haider Sabah Kadhim (Ph.D Microbiology) College of Medicine, Al-Nahrain University-Baghdad, Iraq, ${ }^{4}$ Khitam Razak AlKhafaji (F.I.C.M.S Pathology) College of Medicine, Baghdad University-Baghdad, Iraq, ${ }^{5}$ Kifah Hamdan Abdulghafour (Ph,D Pathology) College of Medicine, Baghdad University-Baghdad, Iraq Iraq.

\section{Address for correspondence:}

Hussam H lazim

Microbiology Department, College of Medicine, Al-Nahrain University

Kadhimiya, Baghdad, Iraq

Tel: +9647801612798

E-mail: hussam_lazim@yahoo.com

\section{How to cite}

Lazim HH, Arif HS, Kadhim HS, Al-Kahafaji KR, Abdulghafour KH. The Association Between Biliary Atresia and Cytomegalovirus Hepatitis. J Nepal Paediatr Soc 2015;35(3):269-273.

doi: http://dx.doi.org/10.3126/jnps.v35i3.13547

This work is licensed under a Creative Commons Attribution 3.0 License.

\section{(c) $\underset{\mathrm{BY}}{\mathrm{Br}}$}

considered as a one of agents that can infect the liver and cause hepatitis ${ }^{9}$. The virus can replicate in both hepatocytes and cholangiocytes, it could directly induce injury in the liver and bile duct system, and induce immune damage in infected cells, revealing inclusion bodies in hepatocytes and vascular epithelial cells, especially in epithelial lining cells of bile duct ${ }^{10}$. This study aimed to determine the role of CMV in children with both chronic hepatitis 
(negative for hepatitis B and C) and have biliary atresia (extra and intra) in the same time.

\section{Materials and Methods}

A retrospective study done on 13 liver tissue paraffin blocks of patients admitted to Gastroenterology and Hepatology Teaching Hospital and Children Welfare Teaching Hospital (Medical City- Baghdad). Specimens collection was done in the period from February 2014 to August 2014, for liver biopsies that were done during the period from 2008 to 2014 for children suffering un explained hepatitis (serologically negative for hepatitis $B$ and C) with biliary atresia ( 9 cases extra and 4 cases intra). Patients records were revised for: Age, sex, clinical manifestations. The diagnosis based on the presence of CMV protein (pp65) by using immunohistochemistry (IHC). Immunohistochemical staining was performed on paraffin blocks after sectioned $(4 \mu \mathrm{m})$. We dewaxed the slides in xylene followed by rehydration via a descending ethanol series (90\%-50\%). The slides were placed in the antigen retrival solution (Sodium citrate buffer, PH 6.0) in water bath 95Co for $5 \mathrm{~min}$. Sections were blocked for endogenous peroxidase $(3 \% \mathrm{H} 2 \mathrm{O} 2$, for $15 \mathrm{~min}$ at room temperature). Drops of protein blocks were added to slide s (15 $\mathrm{min}$ at room temperature). Monoclonal antibody anti CMV pp65 (dilution 1:150, code number: ab49214, Abcam, USA) was added to slides and incubated at 37 Co for $1 \mathrm{hr}$, then placed in 4Co overnight. For visualization, we used a horseradish peroxidase detection system. Finally, positive cells were visualized with the chromogendiaminobenzidine (DAB). After counter staining them with hematoxylin. Dehydration was done and sections were mounted with Disteren Plasticizer Xylene (DPX) and covered by coverslips and examined under light microscope. Positive control slide of Newcomer supply company (USA), this slide are positive for CMV proteins. Single experienced histopathologist revised the biopsies

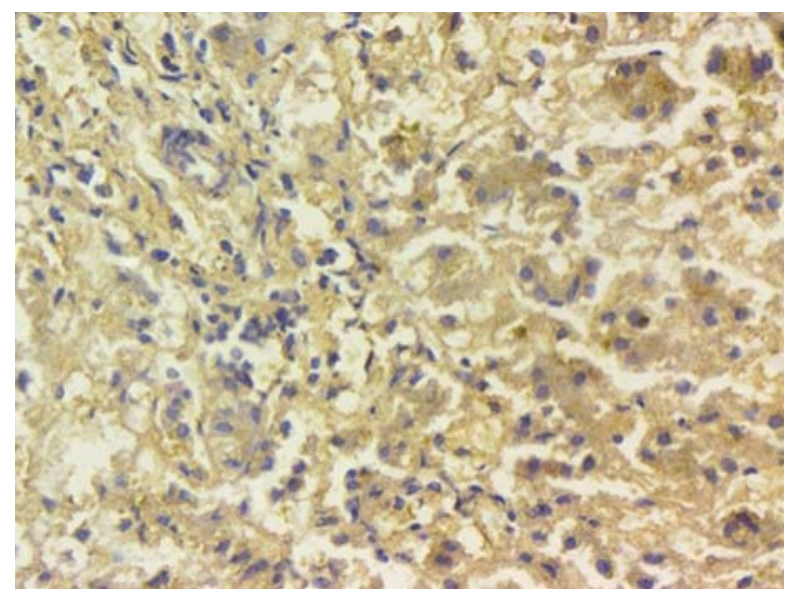

Fig 1: Positive result of CMV pp65 IHC in liver tissue showing brown cytoplasmic and perinuclear stain (IHC stain, 40X) tissue for grading for inflammation and staging for fibrosis. The grading of inflammation and staging of fibrosis were determined according to Knodell histological activity index as follows; inflammation : $\mathrm{Nil}(\leq 2)$, Mild (3-6), Moderate (7-11) and severe $(\geq 12)$ while the fibrosis: Nil (1), Mild (2), Moderate (3) and Severe $(\geq 4)$.

Statistical analysis: The statistical analysis of this study performed with the statistical package for social sciences (SPSS) 19.0 and Microsoft Excel 2013. Categorical data formulated as count and percentage. Chi-square test was used to describe the association of these data. The lower level of accepted statistical significant difference is below 0.05 .

\section{Results}

Positive IHC for CMV pp65 was 10 cases (76.9\%) as shown in Table 1 and Figure 1 . The mean age of patients was (3.8) months with median (3) months (the age range from 2-14 months) and ten (76.9\%) of thirteen were younger than 6 months of age. There was a ratio of nine males to four females (Table 1 ).

From records, clinical symptoms at presentation included jaundice 13 (100\%), followed by pale stools 6 (46.1\%) and hepatosplenomegaly 4 (30.7\%).

According to histopathological reports, there were grading for inflammation and staging for fibrosis (Figure 3 and 4). There were 6 of 8 (75\%) of cases with mild inflammation were positive for CMV pp65IHC. There three out of six (50\%) of cases with moderate fibrosis were positive for CMV IHC. There were 10 (76.9\%) cases showed bile duct proliferation (Figure 2) and $6(46.1 \%)$ with giant cell hepatitis (Figure 3). There were also $6(46.1 \%)$ cases showing bile thrombi in their liver histology (Figure 4).

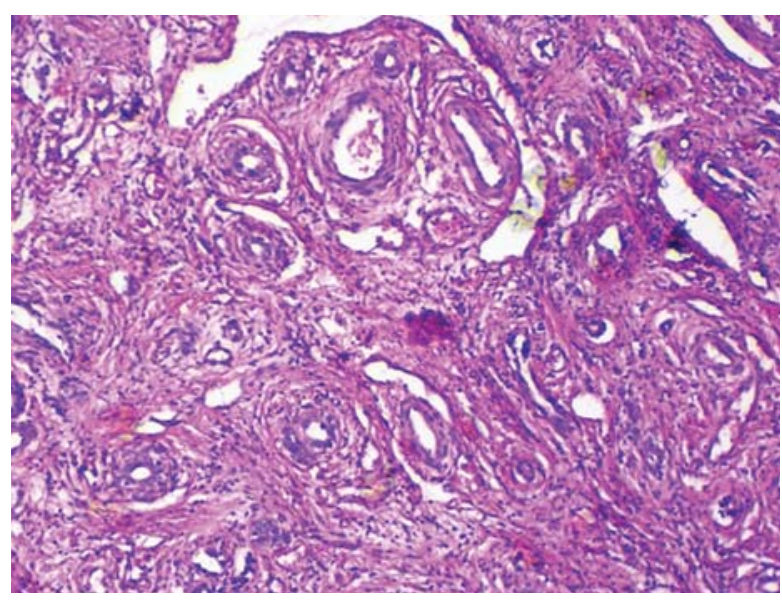

Fig 2: Section showed prominent bile duct proliferation with extensive fibrosis expanding the portal area (H\&E stain, 10X) 


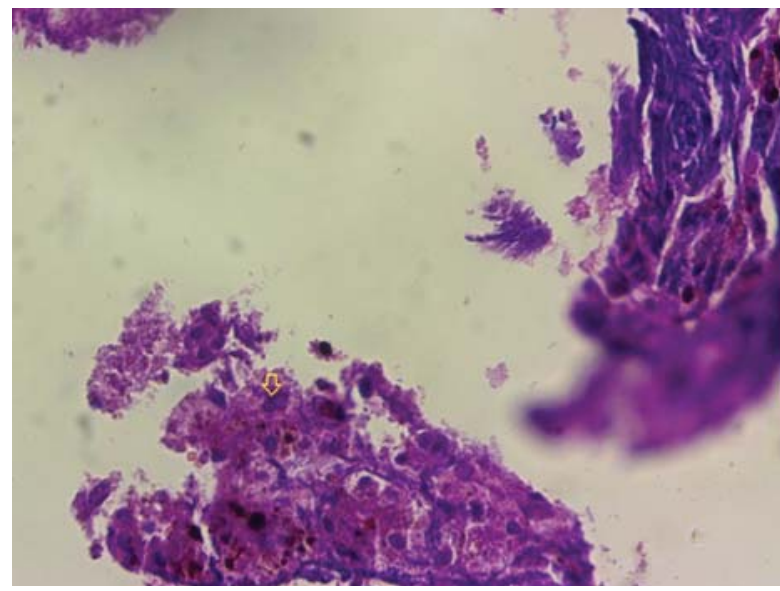

Fig 3: A sheet of hepatocytes with gigantic nuclei (H\&E stain, 40X)

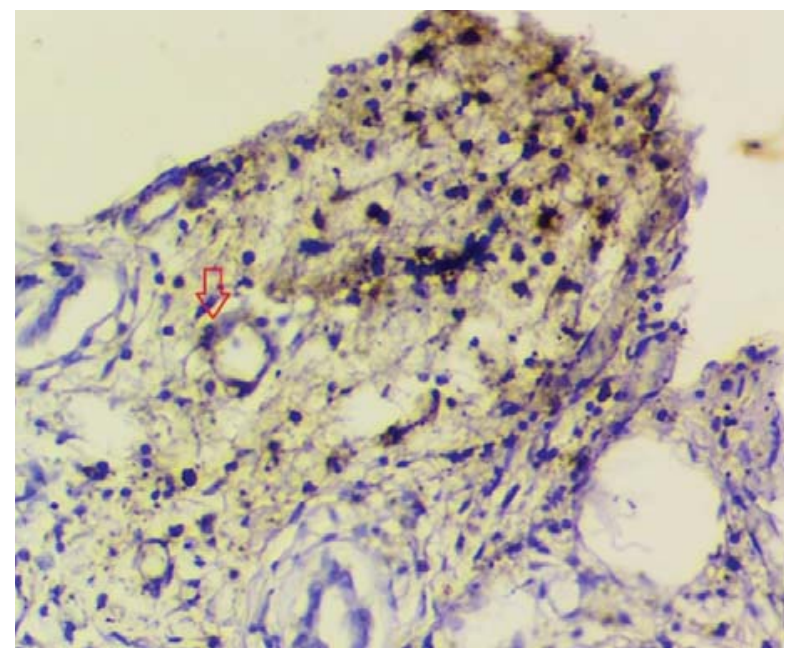

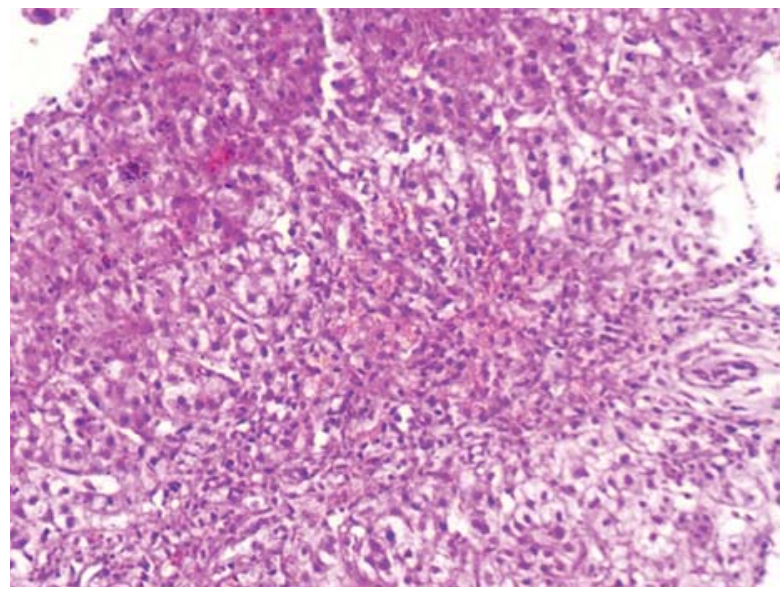

Fig 4: Moderate cholestasis, both hepatocellular and canalicular with bile thrombi and associated with necroinflammatory changes in related to it. Portal area showed paucity of bile duct with prominent bile duct proliferation (H\&E stain, 40X).

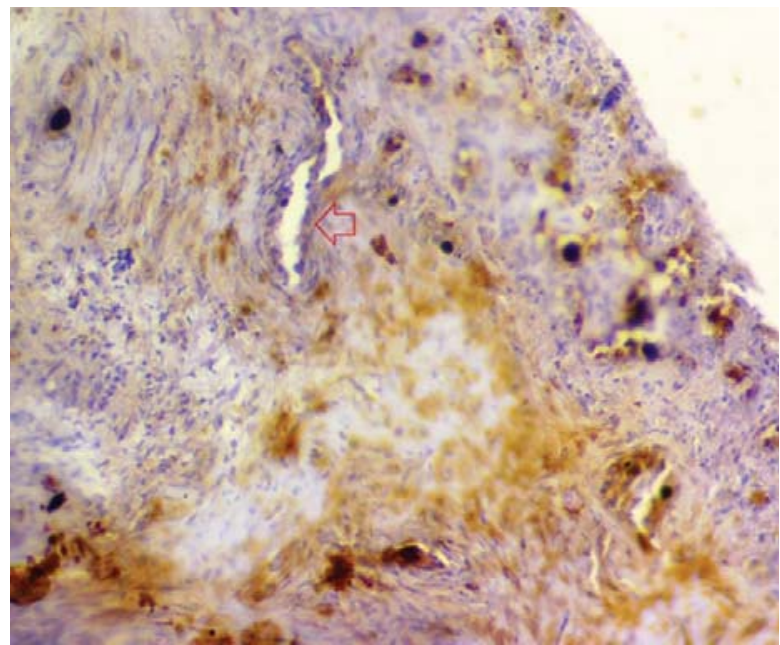

Fig 5 and 6: Bile duct cholangiocytes staining positive of CMV pp65 with perinuclear and cytoplasmic pattern of staining (fig 5 20X, fig 6 40X IHC stain)

Table 1: Characteristics of patients with CMV pp65 IHC result

\begin{tabular}{|c|c|c|c|c|c|c|c|}
\hline \multirow{2}{*}{ CMV pp65 IHC } & \multirow{2}{*}{ Type of BA } & \multicolumn{3}{|c|}{ Signs \& symptoms } & \multirow{2}{*}{ Sex } & \multirow{2}{*}{ Age months } & \multirow{2}{*}{ Patients No. } \\
\hline & & P. stool & HSM & Jaundice & & & \\
\hline +ve & Extra & No & Yes & Yes & $M$ & 2.5 & 1 \\
\hline +ve & Extra & No & No & Yes & $M$ & 4.5 & 2 \\
\hline$+v e$ & Extra & No & No & Yes & $M$ & 3 & 3 \\
\hline+ ve & Extra & No & No & Yes & $\mathrm{M}$ & 2 & 4 \\
\hline -ve & Extra & No & No & Yes & $\mathrm{F}$ & 6 & 5 \\
\hline+ ve & Extra & Yes & Yes & Yes & $\mathrm{F}$ & 3 & 6 \\
\hline -ve & Extra & Yes & Yes & Yes & $M$ & 14 & 7 \\
\hline +ve & Extra & No & No & Yes & $\mathrm{F}$ & 2.5 & 8 \\
\hline +ve & Extra & No & Yes & Yes & $\mathrm{M}$ & 2 & 9 \\
\hline +ve & Intra & Yes & No & Yes & $M$ & 2.5 & 10 \\
\hline+ ve & Intra & Yes & No & Yes & $\mathrm{F}$ & 6 & 11 \\
\hline -ve & Intra & Yes & No & Yes & $M$ & 2.5 & 12 \\
\hline+ ve & Intra & Yes & No & Yes & $M$ & 3.5 & 13 \\
\hline
\end{tabular}

M:male, F:female, HSM:hepatosplenomegaly, P. stool: Pale stool. 
Table 2: Distribution of CMV pp65 IHC according to inflammation

\begin{tabular}{|c|c|c|c|c|c|c|c|c|}
\hline \multirow[b]{2}{*}{$P$ value } & \multicolumn{6}{|c|}{ CMV pp65 IHC } & & \\
\hline & \multicolumn{2}{|c|}{ Positive } & \multicolumn{2}{|c|}{ Negative } & \multicolumn{2}{|c|}{ Total } & & \\
\hline \multirow{6}{*}{0.102} & $\%$ & No & $\%$ & No & $\%$ & NO & & \multirow{6}{*}{ Inflammation } \\
\hline & $0 \%$ & 0 & $0 \%$ & 0 & $0 \%$ & 0 & Nil & \\
\hline & $75 \%$ & 6 & $25 \%$ & 2 & $61.5 \%$ & 8 & Mild & \\
\hline & $100 \%$ & 4 & $0 \%$ & 0 & $30.7 \%$ & 4 & Moderate & \\
\hline & $0 \%$ & 0 & $100 \%$ & 1 & $7.6 \%$ & 1 & Severe & \\
\hline & $76 \%$ & 10 & $23.1 \%$ & 3 & $100 \%$ & 13 & Total & \\
\hline
\end{tabular}

Table 3: Distribution of CMV pp65 IHC according to fibrosis

\begin{tabular}{|c|c|c|c|c|c|c|c|c|}
\hline \multirow[b]{2}{*}{$P$ value } & \multicolumn{6}{|c|}{ CMV pp65 IHC } & & \\
\hline & \multicolumn{2}{|c|}{ Positive } & \multicolumn{2}{|c|}{ Negative } & \multicolumn{2}{|c|}{ Total } & & \multirow{7}{*}{ Fibrosis } \\
\hline \multirow{6}{*}{0.207} & $\%$ & No & $\%$ & No & $\%$ & & & \\
\hline & $100 \%$ & 1 & $0 \%$ & 0 & $7.6 \%$ & 1 & Nil & \\
\hline & $100 \%$ & 2 & $0 \%$ & 0 & $15.3 \%$ & 2 & Mild & \\
\hline & $50 \%$ & 3 & $50 \%$ & 3 & $46.1 \%$ & 6 & Moderate & \\
\hline & $100 \%$ & 4 & $0 \%$ & 0 & $30.7 \%$ & 4 & Severe & \\
\hline & $80 \%$ & 12 & $20 \%$ & 3 & $100 \%$ & 13 & Total & \\
\hline
\end{tabular}

\section{Discussion}

CMV infection is the most frequent congenital infection worldwide and is various in its clinical manifestations ${ }^{11}$. Infants may acquire CMV infection from the mother as a result of intrauterine infection (congenital infection), or through contact with infected genital secretions during passage through the birth canal (perinatal infection), or postpartum through breast feeding (postnatal infection) ${ }^{12}$.

CMV has the ability to replicate in both hepatocytes and cholangiocytes. This virus could directly induce injury in the liver and bile duct system, and induce immune damage in infected cells, revealing inclusion bodies in hepatocytes and vascular epithelial cells, especially in epithelial lining cells of bile duct ${ }^{10}$ (Figures 5 and 6). The swollen bile duct epithelium which is the cause of the unsmooth biliary flow could lead to intra-/ extra- hepatic cholestasis ${ }^{13}$.

In this study the detection of CMV infection was based on presence of virus protein pp65. This protein represents the largest component in virus structure ${ }^{14}$. The expression of this protein coincides with viral lytic replication ${ }^{15}$, also the expression of this protein reflect the active viral infection ${ }^{16}$.

Most of cases in this study were located in the age of less than 6 months; and this may be due to immaturity of immune system, congenital and perinatal infection ${ }^{17,18}$. Similar age prevalence was reported also by Soomro et al $2011^{19}$.
The cases with mild histological inflammation were the highest among others and the cases with moderate histological fibrosis were the highest among others. Regarding inflammation, the explanation of this situation may be due to that inflammation is still in its beginning or inflammation ended from long time with significant fibrosis. While for the fibrosis, the result reflects the extent of persistent or progressive hepatic injury and the small age of patients may be do not give a chance for fibrosis to develop into severe stage ${ }^{20}$. Ten cases with cases with bile duct proliferation. The obstruction of bile duct leads to lack of bile flow and as the result of the pressure of bile cause bile duct proliferation ${ }^{21}$. Also six cases with giant cell hepatitis, it's a common histological finding in infants with neonatal cholestasis $^{22}$.

\section{Conclusions}

From current study, we conclude that CMV is one of the important viruses that can causes hepatitis in infants (whom are negative for hepatitis B and C), also this virus has significant role in pathogenesis of biliary atresia.

Acknowledgements: Nil

Funding: The research is funded by Ministry of Higher Education and Scientific Research / Research and development department - Iraq.

Conflict of Interest: None

Ethics Committee Approval: Ethics committee approval was received for this study from the ethics committee of College of Medicine- Al-Nahrain University. 


\section{References}

1. Hartley JL, Davenport M, Kelly DA. Biliary atresia. Lancet 2009;374(9702):1704-13.

2. Mack CL, Feldman AG, Sokol RJ. Clues to the etiology of bile duct injury in biliary atresia. Semin Liver Dis 2012;32(4):307-16.

3. Rauschenfels S, Krassmann M, Al-Masri AN et al. Incidence of hepatotropic in viruses in biliary atresia. Eur J Pediatr 2009;168(4):469-76.

4. Domiati-Saad R, Dawson DB, Margraf LR et al. Cytomegalovirus and human herpesvirus 6 , but not human papillomavirus, are present in neonatal giant cell hepatitis and extrahepatic biliary atresia. Pediatr Dev Pathol 2000;3(4):367-73.

5. Drut R, Drut RM, Gómez MA et al. Presence of human papillomavirus in extrahepatic biliary atresia. J Pediatr Gastroenterol Nutr 1998;27(5):530-5.

6. Mahjoub F, Shahsiah R, Ardalan FA et al. Detection of Epstein Barr virus by chromogenic in situ hybridization in cases of extra hepatic biliary atresia. Diagn Pathol 2008;3:19. doi: 10.1186/1746-1596-3-19.

7. Mocarski ES, Shenk T, Pass RF. Cytomegaloviruses. In Knipe DM, Howley PM. Editors. Fields virology. 5th ed. Philadelphia. Lippincott Williams. 2007. pp.2701-2772.

8. Badami KG. CMV and transfusions, an old story that's notquite over yet. In J Clin Trans Med 2014;2:7-19.

9. Gallegos-Orozco JF, Rakela-Brödner J. Hepatitis viruses: not always what it seems to be. Rev Med Chil 2010;138(10):1302-11.

10. Varani S, Landini MP. Cytomegalovirus as a hepatotropic virus. Clin Lab 2002;48(1-2):39-44.

11. Leung AK, Sauve RS, Davies HD. Congenital Cytomegalovirus infection. J Natl Med Assoc 2003;95(3):213-18.

12. Kaul A, Sachdeva A. Cytomegalovirus infection in children. In: Dutta AK, Sachdeva A. Advanced in pediatrics. $1^{\text {st }}$ ed. New Delhi. Jaypee. 2007.pp. 265270.

13. Moore SW, Zabiegaj-Zwick C, Nel E. Problems related to CMV infection and biliary atresia. $S$ Afr Med J 2012;102(11 Pt 2):890-2.

14. Varnum SM, Streblow DN, Monroe ME, et al. Identification of proteins in human cytomegalovirus (HCMV) particles: the HCMV proteome. J Virol 2004;78(20):10960-6.

15. Alcendor DJ, Charest AM, Zhu WQ. Infection and upregulation of proinflammatory cytokines in human brain vascular pericytes by human cytomegalovirus. J Neuroinflammation 2012;9: doi: 10.1186/1742-2094-9-95.

16. Jahan M. Laboratory Diagnosis of CMV Infection: A Review. Bangladesh J Med Microbiol 2010;4(2):3944.

17. Kelly D, Coutts AG. Early nutrition and the development of immune function in the neonate. Proc Nutr Soc 2000;59(2):177-185.

18. Mussi-Pinhata MM, Yamamoto AY, do Carmo Rego MA, et al. Perinatal or early-postnatal cytomegalovirus infection in preterm infants under 34 weeks gestation born to CMV-seropositive mothers within a high-seroprevalence population. J Pediatr 2004;145(5):685-8.

19. Soomro $G H, A b b a s ~ Z$, Hassan $M$ et al. Is there any association of extra hepatic biliary atresia with cytomegalovirus or other infections? J Pak Med Assoc 2011;61(3):281-3.

20. Kumar $\mathrm{V}, \mathrm{Abbas} \mathrm{AK}$, Fausto $\mathrm{N}$ et al. Tissue renewal, regeneration, and repair. In: Kumar V, Abbas $\mathrm{AK}$, Fausto $\mathrm{N}$ et al. Editors. Robbins and Corton pathologic basis of disease.8th ed.Philadelphia. Elsevier. 2010. pp79-110.

21. Burt AD, Macsween R.N.M. Bile ducrt proliferation-its true significance? Histopathology 1993;23(6):599-602.

22. Torbenson M, Hart J, Westerhoff M et al. Neonatal giant cell hepatitis: histological and etiological findings. Am J Surg Pathol 2010;34(10):1498-1503. 